\title{
Optimization of Truck Chassis Frame using
}

\section{Ansys}

\author{
Ramesh Krishnan, K. Gnanasekaran, M. Thayumanavan, R.Suganthini Rekha, D. Murali
}

\begin{abstract}
Chassis frame is the skeleton of an automobile industry. It must be hard to resist the adequate shock, twist, vibration and bending stress occurred in operating condition. The material selection and design of chassis frame plays vital role in automobile industry. The chassis can resist the total load acting on the system and it holds the entire body of an automobile. So, highest stress, most equilateral stress and deflection are considerable factors while design of the chassis. In this Paper stainless steel, epoxy and aluminum are the different material used for chassis frame and it is modeled using solid works software and the Finite element analysis has been carried out with using ANSYS. The chassis frame has been optimized based on the most shear stress, equivalent stress and deflection and also responsiveness inspection is carry through to minimize the weight.
\end{abstract}

Keywords: Chassis frame, Vibration, Automobile, Sensitivity Analysis.

\section{INTRODUCTION}

The air pollution is due to the burning of fuel in automobiles and power plants etc. When the increase of vehicle quantity the utilization of fuel also increases respectively. The deficiency of the resource the fuel makes the amount raises occasionally. The emission out of the vehicle causes the air pollution in the environment which is hazardous to the living things. Many steps to be taken to reduce the air pollution in the environment to protect the species, one among the step is reduce the burning of fuels in automobiles. Unfortunately it is highly difficult to reduce the number vehicles in the society. The other prevention is to minimize the weight of the vehicles, which leads to increase the efficiency. When the efficient level of engine is attained , the emission maintains the low level and the essential level of fuel usage is low, which reduce the air pollution. This paper is mainly focused to reduce the usage of fuel by reducing the weight of the under seal of vehicle. The consumption of the fuel also minimized. Izzudin B. Zaman et al [1 ] has made a research on the uses of dynamic interaction and model revised techniques. This method is mainly used to improve more

Revised Manuscript Received on February 05, 2020.

* Correspondence Author

Ramesh Krishnan, Assistant Professor, Department of Engineering and Technology, St. Joseph's Institute of Technology, Chennai, India.

K. Gnanasekaran, Assistant Professor, Department of Engineering and Technology, St. Joseph's Institute of Technology, Chennai, India.

M. Thayumanavan, Department of Engineering and Technology, St. Joseph's Institute of Technology, Chennai, India.

Dr. R. Suganthini Rekha, Department of Mechanical Engineering, Bharathidasan University, Tiruchirappalli, Tamil Nadu, India.

D. Murali, Assistant Professor, Department of Engineering and Technology, St. Joseph's Institute of Technology, Chennai, India.

(c) The Authors. Published by Blue Eyes Intelligence Engineering and Sciences Publication (BEIESP). This is an open access article under the CC BY-NC-ND license (http://creativecommons.org/licenses/by-nc-nd/4.0/) desirable version of current truck basis with a precision of 1 jillion and to for confirmation of analysis models of truck basis. The dynamic topology of truck basis such as frequency and system structure are find out using analysis method From the initial result, the analysis display the truck basis expert $1^{\text {st }}$ torsion mode for $1^{\text {st }}$ frequency, $1^{\text {st }}$ bending mode for $2^{\text {nd }}$ natural frequency, $2^{\text {nd }}$ torsion mode for $3^{\text {rd }}$ natural frequency and $2^{\text {nd }}$ bending mode for $4^{\text {th }}$ natural frequency. Dave Anderson et al[2] et al analyzed a Multi-Body Dynamic Model of the Tractor-trailertruck for ride quality prognosis. The study involves to initiate the distribution of mass and flexibility of the vehicle shape e.g. fixtre ladder, the uneven character of shock absorbers, recreate the basics system movement that involve to manage and gives the final value of the acceleration, velocity and displacement to estimate and to finalize the ride quality. RoslanAbd Rahman et al[3] made a research on stress analysis of high duty truck basis by make use of a trade analysis package ABAQUS. The design alterations shows that the stress may be reduced to provide better fatigue life of systems . The material used for this study is ASTM low alloy steel at $710^{\circ} \mathrm{C}$ with $555 \mathrm{MPa}$ of yield strength and $620 \mathrm{MPa}$ of tensile strength for basis founds the ultimate stress $386.9 \mathrm{MPa}$ at analytic point obtained at entry of chassis The evaluate point is placed at component 86105 and node 16045, placed at contact with the bolt from this he says that this evaluate point is an initial to expected failure.

\section{EXPERIMENTAL WORK}

\section{A.PROBLEM STATEMENT}

The use of transportation increases in everyday of life . The amount of vehicles raises due to human being usage increases because now a day's people opinion to utilize their own transport instead of public transport. In order to reduce the air pollution The initial procedure to minimize the number of vehicles and reduce the consumption of fuel. The emission in the vehicle is also related to the fuel consumption and weight of the vehicle. Preventive step is to be minimize the load of the frame and chassis, which can minimize the usage of fuel at the same time strength of the chassis, need to be maintain for the given load

\section{GENERAL OBJECTIVES:}

The aim of the research are as follows to:

- assess the exiting frame.

- remake the Truck frame.

- Resolve the complex failure using Ansys software. 


\section{Optimization of Truck Chassis Frame using Ansys}

\section{B. Design of Chassis}

.The deisign of trcuck chassis frame has been done by using cad software as shown in fig 1

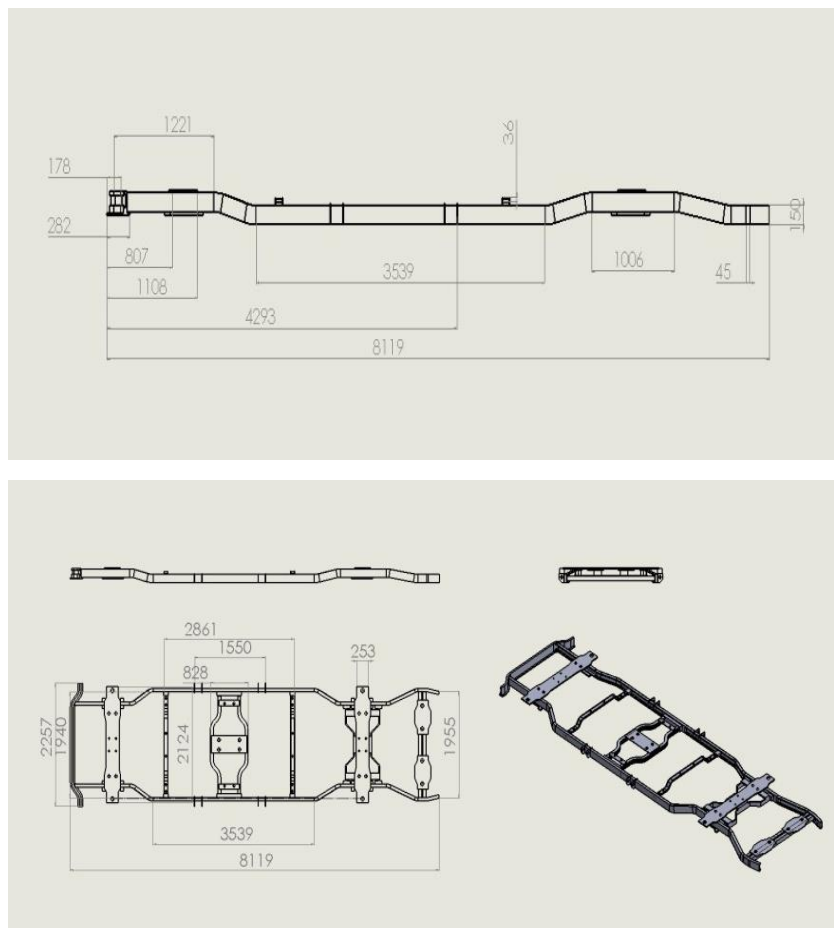

Fig.1. Cad modeling Diagram (Side view)

\section{DESIGN TOOL:}

\section{SOLIDWORKS}

Solid works is highly productive three dimensional tool which is interlinked with analytical tool and to make automation to help stimulate the physical behavior such as kinematics, dynamics, stress, and deflection, vibration and temperature .it also used to measure the stress, strain and displacements. Design pattern shows how to the create the components need to response to alter and updates. For example, you need to make a hole at the top of a water bottle to stay at the top surface, need to consider the dimensions of bottle. Solid Works permit the user to indicate the hole size on the top surface, and will then integrity their design purpose no matter what size they need to modify the bottle .

\section{D.MATERIALS USED}

\section{EPOXY}

Epoxy resin is advance thermosetting reins used in composites for a variety of manufactured products and is suitable for molding process. They are reasonably stable to chemical attacks and are excellent adherents having slow shrinkage during curing and no emission of volatile gases. These advantages, however, make the use of epoxies rather expensive. Also, they cannot be expected beyond a temperature of $140^{\circ} \mathrm{C}$. Their use in high technology areas where service temperatures are higher, as a result, is ruled out.

\section{STAINLESS STEEL}

Stainless steel is an alloy of iron with a minimum of $10.5 \%$ chromium. Chromium is included to resist the rust. It is widely used in many applications and also it provides the excellent corrosion resistance. It can be machined at low speed and stable feed which will minimize this alloys propensity to work cohesion. Durable than 304 stainless with a long straggly chip, the use of chip cutter is suggested.

\section{ALUMINIUM}

Aluminum is a soft, ductile, corrosion resistant and has a high electrical conductivity it is widely used for foil and conductor cables. Among many types AA6063 material is selected because the weight of material is less, medium strength alloy and it is mainly used in intricate extrusions.

\section{RESULTS AND DISCSSION}

ANSYS is a high performance computational fluid dynamics software tool that delivers reliable and accurate solutions ANSYS develops and markets finite element analysis software which is used to simulate the engineering problems it helps to develop the computer models of structures, electronics or machine component to analyze the strength ,toughness, elasticity, temperature distribution, electromagnetism and fluid flow

\section{A. EPOXY}

\section{Table- I Stress, Strain and Deformation results for} Epoxy

\begin{tabular}{|c|c|c|}
\hline Variables & Minimum Value & Maximum Value \\
\hline Stress & $901.51 \mathrm{pa}$ & $2.2644 \mathrm{e} 8 \mathrm{pa}$ \\
\hline Strain & $7.7684 \mathrm{e}-9 \mathrm{~m} / \mathrm{m}$ & $0.00075562 \mathrm{~m} / \mathrm{m}$ \\
\hline Deformation & $0.00021666 \mathrm{~m}$ & $0.011956 \mathrm{~m}$ \\
\hline
\end{tabular}

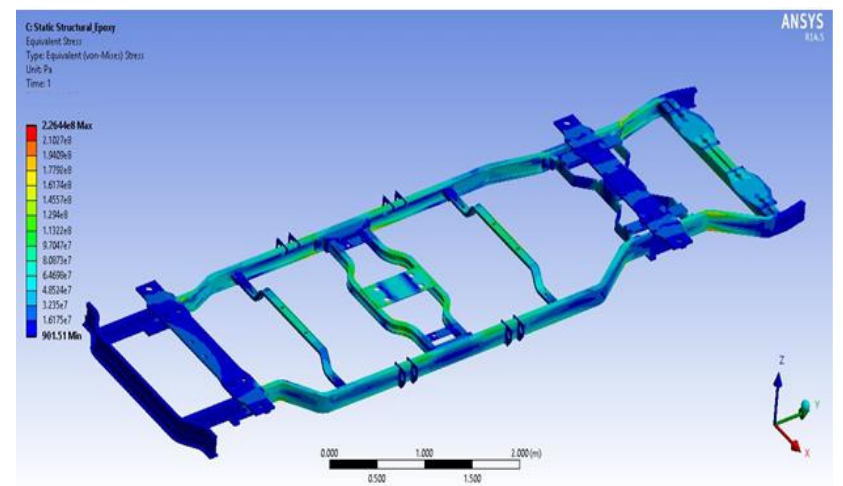

Fig.2. Stress analysis for Epoxy

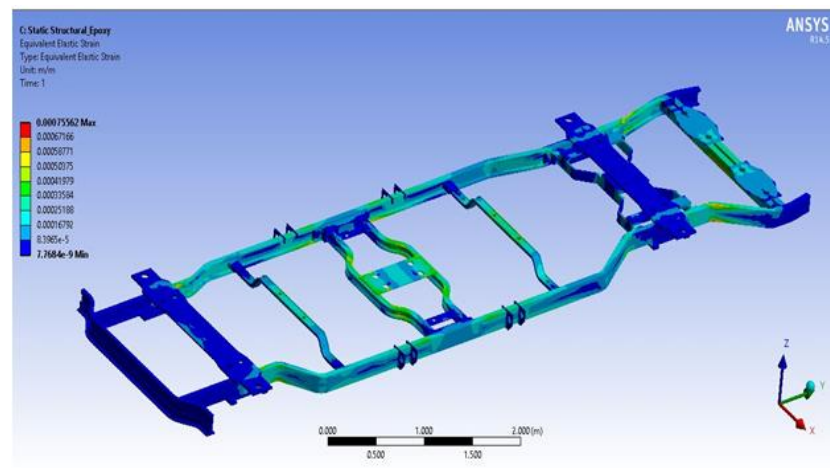

Fig.3 Strain analysis for Epoxy

Published By:

Blue Eyes Intelligence Engineering

\& Sciences Publication 


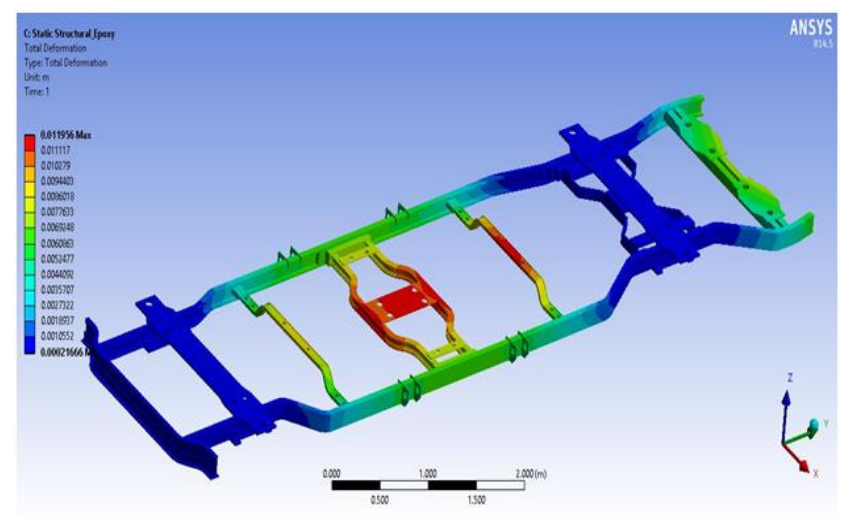

Fig.4 Deformation analysis for Epoxy

From the table I and Fig 2,3, and 4 clearly shows the minimum and the maximum values for stress, strain and deformation for epoxy material when compare to the stress strain and deformation with aluminum and steel, the deformation of epoxy is reduced in truck chassis frame material.

\section{B.STAINLESS STEEL}

Table- II Stress, Strain and Deformation results for Stainless Steel

\begin{tabular}{|c|c|c|}
\hline Variables & Minimum Value & Maximum Value \\
\hline Stress & $901.47 \mathrm{pa}$ & $2.2644 \mathrm{e} 8 \mathrm{pa}$ \\
\hline Strain & $1.1652 \mathrm{e}-8 \mathrm{~m} / \mathrm{m}$ & $0.0011334 \mathrm{~m} / \mathrm{m}$ \\
\hline Deformation & $0.00032499 \mathrm{~m}$ & $0.017934 \mathrm{~m}$ \\
\hline
\end{tabular}

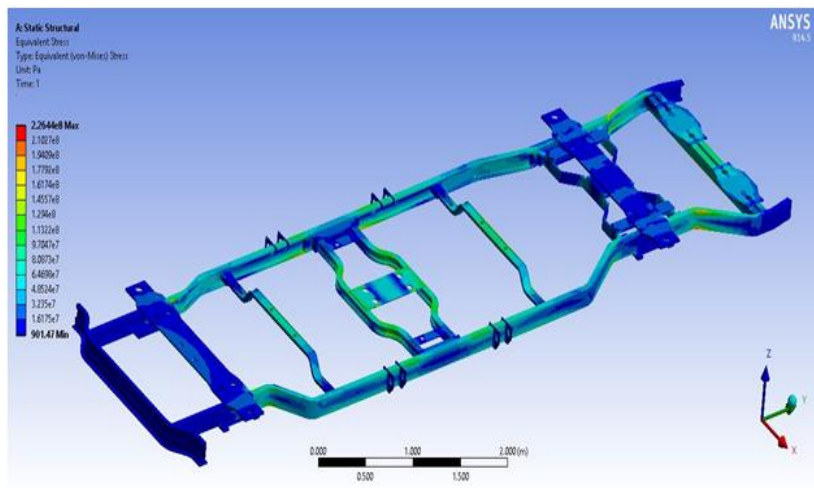

Fig.5 Stress analysis for Steel

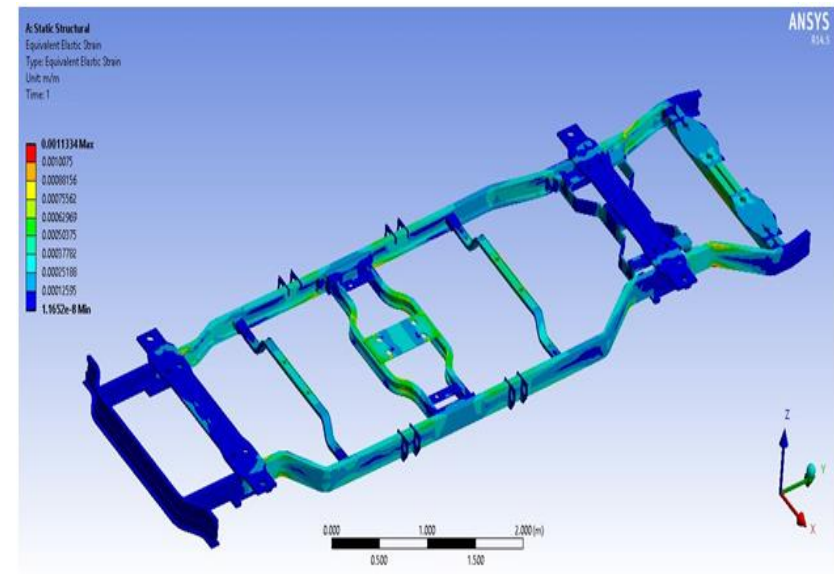

Fig.6 Strain analysis for Steel

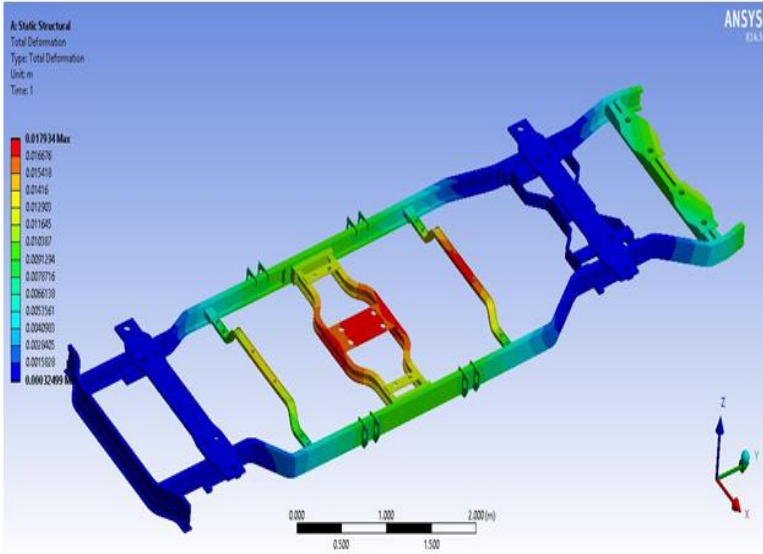

Fig.7 Deformation analysis for Steel

From the Table II and fig 5, 6, and 7 clearly shows the minimum and the maximum values for stress, strain and deformation for stainless steel material when compare to the stress ,strain and deformation with epoxy and Aluminum, the stress and strain is reduced in the stainless steel material .

\section{C.ALUMINIUM}

Table 3 Stress, Strain and Deformation results for Aluminum

\begin{tabular}{|c|c|c|}
\hline Variables & Minimum Value & Maximum Value \\
\hline Stress & $923.79 \mathrm{pa}$ & $2.2671 \mathrm{e} 8 \mathrm{pa}$ \\
\hline Strain & $3.5266 \mathrm{e}-8 \mathrm{~m} / \mathrm{m}$ & $0.0031965 \mathrm{~m} / \mathrm{m}$ \\
\hline Deformation & $0.00090464 \mathrm{~m}$ & $0.050484 \mathrm{~m}$ \\
\hline
\end{tabular}

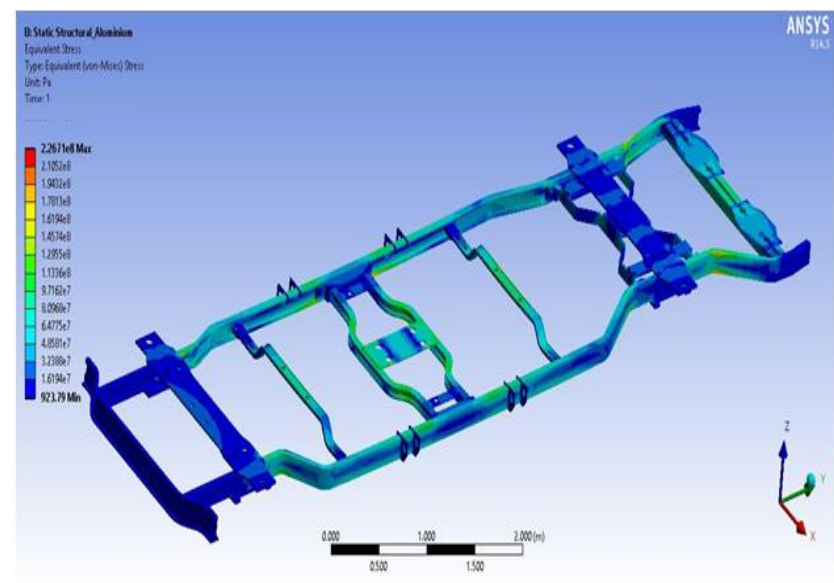

Fig.8 Stress analysis for Aluminum

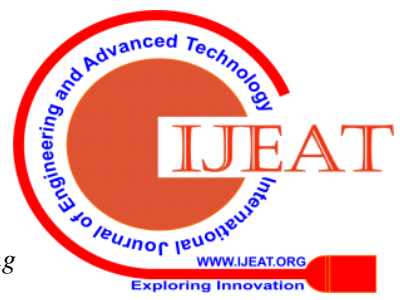




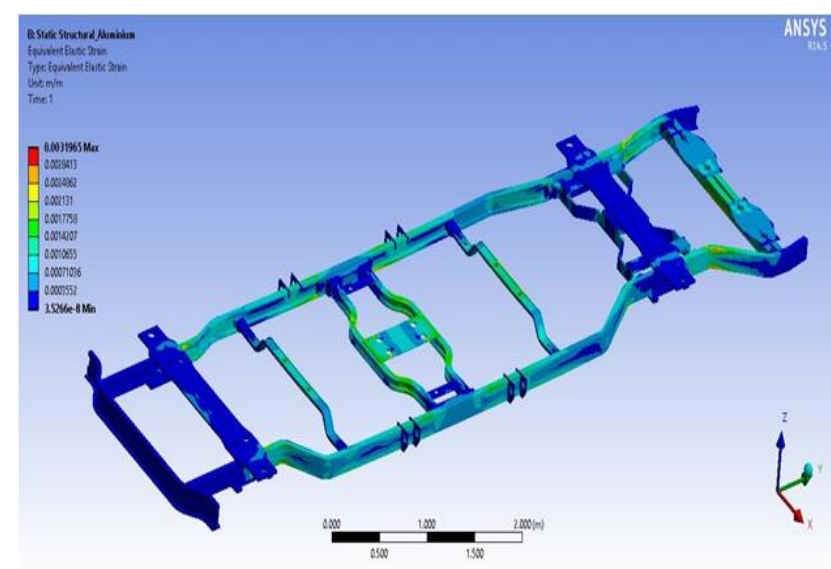

Fig.9 Strain analysis for Aluminum

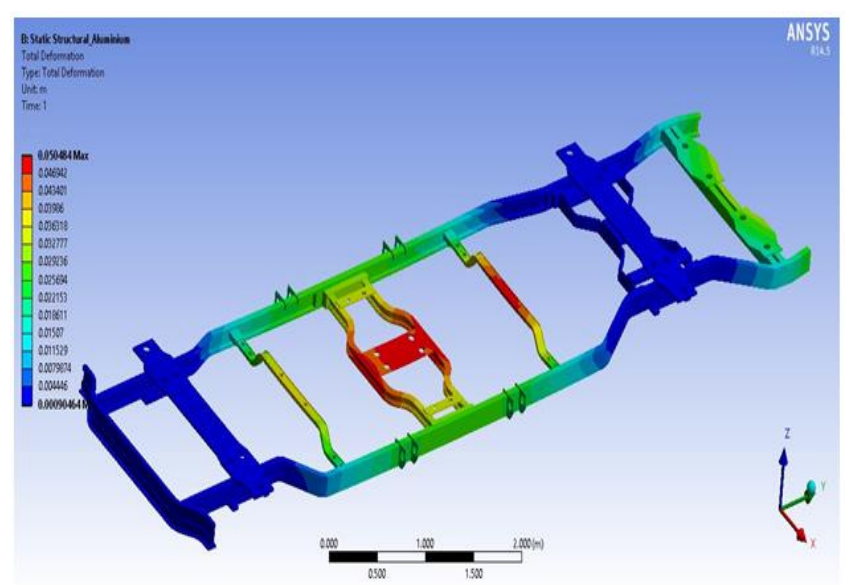

Fig.10 Deformation analysis for Aluminum

From the table III and Fig 8, 9, and 10 clearly shows the minimum and the maximum values for stress, strain and deformation for Aluminum material when compare to the stress, strain and deformation with epoxy and stainless steel, the stress and strain is increased in the aluminum material

\section{CONCLUSION}

The analysis is done on stainless steel ,epoxy, and aluminum material by using ansys software. the experiments were conducted on stress, strain and deformation of material .the comparison of steel, aluminum, and epoxywere done it shows that aluminum and epoxy is high weight when compared to steel. Based on the results, Stress for three materials are stable and the strain values is varied according to the material properties like strength and stiffness .From the results, it is observed that the stainless steel provides the high strength and more economical than the conventional materials.

\section{REFERENCES}

1. N A Z Abdullah, M S M Sani, M M Rahman and I Zaman“A review on model updating in structural dynamics'’International Conference of Mechanical Engineering Research (ICMER 2015)

2. Dave Anderson, Gred Schade, Greg Schade, Stacey Hamill and Patric O'Heron“ Development of a Multi-Body Dynamic Model of a Tractor-Semitrailer for Ride Quality Prediction ", Journal of Commercial Vehicles Vol. 110, Section 2 (2001), pp. 351-362

3. Roslan Abd Rahman, Mohd Nasir Tamin, Ojo Kurdi "Stress Analysis Of Heavy Duty Truck Chassis as a preliminary Data For Its Fatigue Life Prediction Using FEM" Journal Mekanikal, No. 26(2008), 76 - 85

4. Karaoglu, C. and Kuralay, N.S. "Stress Analysis of a Truck Chassis with Riveted Joints", Elsevier Science Publishers. Netherlands, Vol. 38, 1115-1130.

5. Sujatha C \& V Ramamurti, "Bus Vibration Study-Experimental
Response to Road Undulation”, International Journal of Vehicle Design, Vol. 11(1990), no. 4/5, pp. 390-400, 1990.

6. H J Beermann, English translation by Guy Tidbury, The Analysis of Commercial Vehicle Structures, Verlag TUV Rheinland GmbH Koln-1989.

\section{AUTHORS PROFILE}

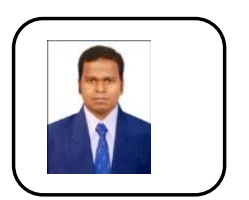

Ramesh Krishnan, has finished his Bachelor of Engineering degree in the year of 2008 from C. Abdul Hakeem College of Engineering and Technology, Vellore and his Master Degree in the year of 2012 from College of Engineering, Guindy. Now he is working as a Assistant Professor in St. Joseph's Institute of Technology, Chennai. He is a Life time Membership in Indian Society for Technical Education. He has published 3 research paper in international journal.

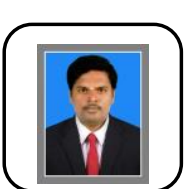

K. Gnanasekaran, has completed his Bachelor of

Engineering degree in the year of 2015 from Dhanalakshmi Srinivasan College of Engineering and Technology, Chennai and his Master Degree in the year of 2017 from St. Joseph's College of Engineering, Chennai. Now he is working as a Assistant Professor in St. Joseph's Institute of Technology, Chennai. He is a Life time Membership in Indian Society for Technical Education. He has published 3 research paper in international journal.

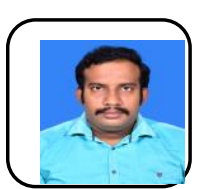

M.Thayumanavan, obtained his Diploma in mechanical engineering in the year 2011 from vel tech polytechnic college,Chennai. B.E degree in Mechanical Engineering in the year 2014 from Jeppiaar Eneginering College ,Chennai. M.E degree in manufacturing engineering in the year 2017 from St.joseph's college of engineering, chennai . He has published 1 research paper in international journal

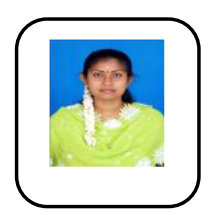

Dr.R.Suganthini Rekha, has completed her Bachelor of Engineering from Madras University, Master of Engineering from College of Engineering, Guindy, Anna University and Doctorate of Philosophy in Engineering domain from St.Peter's Institute of Higher Education and Research in the Department of Mechanical Engineering. She has also completed her M.B.A with specialization in Educational Management from Madras University, Post Graduate Diploma in Human resource Management from Anna University, Master of Science in Applied Psychology from Bharathidasan University. She has received award in 2016 as" Excellent Professional Achievement Award" and "Innovative Technologist \& Dedicated Teaching Professional" in 2017.She has published 15 papers, authored 1 book titled "Maintenance Engineering". She is a life member of Indian Society of Technical Education and National Institute of Quality \& Reliability. She has as filed one patent. Her research areas are product design \& development mechatronics, composites, biodegradable materials, energy systems \& environment, lean manufacturing and multidisciplinary areas.

D. Murali, has completed his Bachelor of Engineering degree in the year of

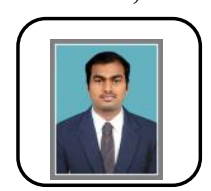
2010 from RMK Engineering College, Chennai and his Master Degree in the year of 2016 from St. Joseph's College of Engineering. Now he is working as a Assistant Professor in St. Joseph's Institute of Technology, Chennai. He is a Life time Membership in Indian Society for Technical Education. He has published 2 research paper in international journal. 